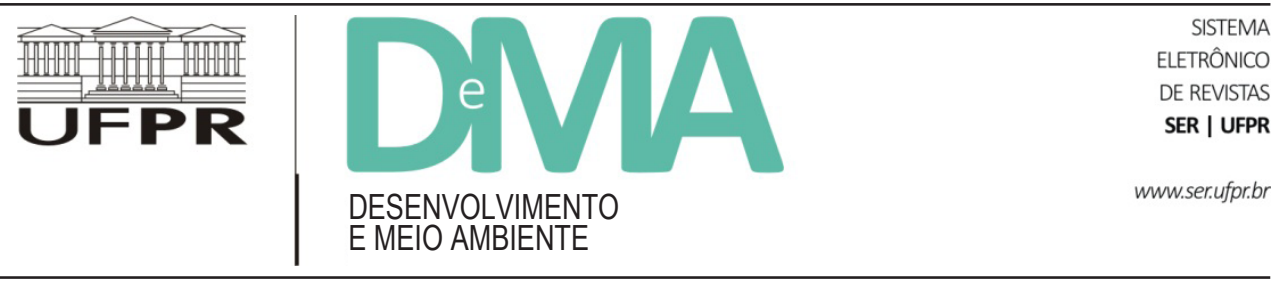

\title{
Hacia una antropología ambiental para la apropiación social del patrimonio biocultural de los pueblos indígenas en América Latina
}

\author{
Em direção a uma antropologia ambiental para a apropriação do \\ patrimônio biocultural dos povos indígenas na América Latina
}

\section{Towards an Environmental Anthropology for the Appropriation of Biocultural Heritage of Indigenous Peoples in Latin America}

\author{
Eckart BOEGE ${ }^{1 *}$ \\ ${ }^{1}$ Instituto Nacional de Antropología e Historia (INAH), México. \\ *E-mail de contacto: eckart.boege@gmail.com
}

Artículo recibido el 11 de noviembre, 2015, versión final aceptada el 1 de desembro, 2015.

RESUMEN: Con el concepto de patrimonio biocultural, el siguiente artículo busca contribuir a la discusión de las alternativas a las crisis socioambientales generadas por la globalización y la transnacionalización de la economía. El cambio climático constituye el mayor fracaso del mercado jamás visto en el mundo, y este fracaso interactúa con otras “imperfecciones del mercado". La ecología política vista desde el sur no confía en que la globalización, aún con su economía verde, pueda resolver la crisis ambiental global. Pobreza y ecocidio como parte de ese neocolonialismo neoliberal es consecuencia intrínseca del extractivismo a ultranza que estamos padeciendo en la América Latina: nos detuvimos con millones de hectáreas de soja y maíz transgénico, deforestaciones masivas para plantaciones forestales, concesiones para la minería industrial, megahidroeléctricas, fractura hidráulica para extracción de gas esquisto y otros hidrocarburos son algunos ejemplos de nuevos paisajes que empiezan a invadir nuestros países. Desde los movimientos de la pluriversidad en la América Latina, de la interculturalidad crítica, de las filosofías indígenas, de la memoria biocultural y la importancia ecológica de las sabidurías tradicionales, de una interculturalidad crítica y desde el vivir bien, se trata de buscar enfoques que superen esa dualidad abismal de naturaleza cultural, la idea de occidente de una naturaleza y cuerpo instrumental. Desde el año 2000 se está perfilando un concepto nuevo que es de la diversidad biocultural. Se le agrega la idea de patrimonio escrito con minúsculas como componente vital para "proteger lo nuestro". En este trabajo se intenta vincular este concepto de patrimonio biocultural con la epistemología del sur.

Palabras claves: patrimonio biocultural; crisis socioambiental global; diversidad; epistemología del sur; pueblos indígenas. 
RESUMO: O seguinte artigo tenta contribuir com o conceito de patrimônio biocultural para a discussão das alternativas às crises socioambientais geradas pela globalização e pela transnacionalização da economia. A mudança climática constitui o maior fracasso do mercado visto no mundo e interage com outras imperfeições do mercado. A ecologia política vista a partir do sul não confia que a globalização, mesmo com a sua economia verde, possa resolver a crise ambiental global. Pobreza e ecocídio como parte deste neocolonialismo neoliberal são a lógica intrínseca do extrativismo que estamos padecendo na América Latina: Colinas verdes com milhões de hectares de soja e milho transgênico, desmatamentos massivos para plantações florestais, concessões para a mineração industrial, mega-hidroelétricas, fratura hidráulica para extração de gás de xisto e outros hidrocarbonetos são alguns exemplos que começam a invadir nossas paisagens. A partir dos movimentos da pluriversidade da América Latina, da interculturalidade crítica, das filosofias indígenas, da memória biocultural, da importância ecológica dos saberes tradicionais e do viver bem, trata-se de buscar enfoques que superem essa dualidade abissal natureza-cultura e a ideia instrumental do ocidente sobre natureza e corpo. Desde o ano 2000 está se esboçando um conceito novo, que é o da diversidade biocultural. Este conceito acrescenta a ideia de patrimônio (escrito com letras minúsculas) como componente vital no sentido de "defender o que é nosso". Neste trabalho, procura-se vincular este conceito de patrimônio biocultural com a epistemologia do sul.

Palavras-chave: patrimônio biocultural; crise ambiental global; epistemologia do sul; boa vida; povos indígenas.

ABSTRACT: This work incorporates the concept of biocultural heritage to the discussion on the alternatives for the socioenvironmental crises promoted by globalization and transnationalization of the economy. Climate global change represents the largest failure the markets have ever seen, and interacts with other market imperfections. From a southern perspective, environmental politics does not trust globalization as an alternative to solve global environmental crisis, even under a "green economy" concept. Poverty and ecocides as components of the neoliberal colonialism are the intrinsic logic to the extractivism suffered in Latin America: green fields with millions of hectares of transgenic corn and soya, massive deforested areas for timber plantations, mega hydro electrical projects for mining concessions and fracking for shell gas extraction are just a few examples which have invaded our landscapes. From the multi diverse movements in Latin America, the critical interculturalism, indigenous philosophies, biocultural memory, the ecological importance of traditional knowledge and well living, it seeks approaches that go beyond this abysmal nature-culture duality and the instrumental western idea about body and nature. Since 2000 the concept of biocultural diversity has emerged and the idea of heritage was added to this concept, as an essential component of "defend what is ours" idea. In this work I intend to link the concept of biocultural heritage with the southern epistemology.

Keywords: biocultural heritage; global socio-environmental crisis; diversity; Southern epistemology; indigenous communities.

\section{Una nota introductoria}

Este trabajo se preparó para el Seminario Permanente de Cultura y Representaciones Sociales, que se organizó en el Instituto de Investigaciones Sociales de la Universidad Nacional Autónoma de México, cuyo tema fue "La crisis ambiental desde la perspectiva de las ciencias sociales. Construyendo sociedades sustentables desde el Sur".

La plataforma de discusión de los participantes del Seminario bajo la conducción de Gilberto Gimenez y Enrique Leff, nos convocó a no limitarnos a discutir los paradigmas teóricos globales y a ver sus aplicaciones en nuestra región, sino a construir un campo socio-ambiental capaz de analizar problemas críticos: Los derechos colectivos a los bienes comunes, los conflictos de apropiación de territorios y de los patrimonios bio-culturales y las formas de propiedad común de los recursos naturales; buscamos construir así una sociología y unas ciencias sociales que orienten los procesos de construcción política de la sustentabilidad desde una nueva racionalidad social: de una racionalidad ambiental 
fundada en los potenciales ecológicos y culturales de la región. Desde esta perspectiva consideramos que desde sus estudios en el campo de la sociología ambiental, de la economía ecológica y la ecología política, de los estudios culturales y la antropología ambiental, de la sociología del derecho ambiental, de las formas de propiedad común y de la geografía ambiental, podemos avanzar en la construcción del campo socio-ambiental y de la ecología política en América Latina. Imaginar ideas para la construcción de un campo estratégico, no de un campo de ciencias ambientales en general, sino de unas ciencias sociales, guiadas por la imaginación sociológica.

Construir el imaginario socioambiental desde la ecología política requiere una serie de mediaciones teórico y metodológicas que nos sugieren los propios movimientos socioambientales a distintas escalas. Partí de las conclusiones de la conferencia inaugural que nos regaló Enrique Leff (Leff, 2014) ${ }^{1}$ :

Se trata de atraer la teoría de la complejidad de la postmodernidad y territorializarla a la política del sur. Una política de la diferencia, de la ontología de la diferencia del pensamiento y de la otredad. Lo que aquí se juega es la capacidad de la sociología de mirar lo otro empezando por la vinculación distinta con la naturaleza, pensando también en las raíces de la problemática socioambiental, no sólo desde el potencial ecológico. Pensar una sociedad negentrópica que no es visible desde el norte. En el norte no se concibe la idea de que la negentropía es fuente de la creación de la riqueza desde la diferencia, desde la diversidad cultural y de la reapropiación de la naturaleza. La intención de la descolonización del saber y la construcción de la filosofía de la vida, la del "vivir bien” (Sumak Kawsayen Aymara) es sólo una manera de ver los pensamientos de los pueblos del sur que reclaman su derecho de ser tradicionales, el derecho de ser indígenas en su habitad desde el habitus y desde el humus de sus tierras, de sus mundos. Es una dinámica cosmopolita del ser tra- dicional, desde la reinvención de sus identidades. No se trata de volver atrás. En este mundo de ser indígena y de la complejidad ambiental, lo que está vivo son los procesos de descolonización del saber, mundos de vida diferentes desde la reapropiación de sus territorios y de sus identidades. En esta lucha de poder con la definición de la sustentabilidad está implicada la definición de la vida misma y de la reapropiación de la vida en el planeta, hacia la cual debemos de caminar en imaginación sociológica o antropológica. Esta explosión hay que atraerla a un diálogo de saberes entre los pueblos indígenas, los movimientos sociales y la academia.

\section{La ecología política y el patrimonio biocultural.}

Para atraer la teoría de la complejidad, de la postmodernidad y territorializarla a la política del Sur, según la fórmula de EnriqueLeff - el concepto de patrimonio biocultural podría contribuir en generar mediaciones teórico y metodológicas transdisciplinarias entre la teoría general de la crisis socioambiental y los movimientos de resistencia socioambiental de diversos actores sociales incluyendo los pueblos indígenas y comunidades equiparables.

\begin{abstract}
A través del concepto de diversidad y patrimonio biocultural podemos explorar la organización de comunidades negentrópicas; ver cómo los pueblos de la tierra han verificado, construido tal verdad como posibilidad de ser (Leff, 2014, p. 341).
\end{abstract}

El concepto de patrimonio biocultural sería entonces una herramienta teórica, metodológica y práctica para analizar y aterrizar (en territorios) relaciones complejas de "un mundo donde caben otros mundos", fórmula neozapatista autonómica y anticapitalista de la diversidad para una ontología y su ser político alternativo que no

\footnotetext{
${ }^{1}$ Transcripción de las conclusiones de la conferencia magistral inaugural dictada por Enrique Leff en el Seminario Permanente de Cultura y Representaciones Sociales. Una Sociología para la sustentabilidad: Desafio teórico-epistemológico para las ciencias sociales y para la construcción de una racionalidad ambiental. IIS-UNAM, México, Febrero 17- 2014.
} 
cree en las soluciones de la globalización del capitalismo reinante.

Nos dice de Souza Santos (2009, p. 187) en la Epistemología del Sur cuando se refiere a la preservación de la biodiversidad por las formas de conocimientos rurales e indígenas:

¿No deberíamos ser (estar E.B) sorprendidos por la abundancia de los conocimientos, modos de vida, los universos simbólicos y las sabidurías que han sido preservados para sobrevivir en condiciones que están basados en la tradición oral? ¿El hecho de que nada de eso habría sido posible a través de la ciencia?

y la otra idea del mismo autor citada por Avila \& Pohlenz (2012, p. 70):

[...] no hay justicia social global sin justicia cognitiva; o sea, sin justicia de conocimientos. La diversidad del mundo sigue inagotable, no hay, por tanto, teoría general que pueda organizar toda esa realidad...

La ecología política para la defensa de la diversidad y el bien común, explora las relaciones de poder entre la sociedad y la naturaleza, incrustadas en los intereses sociales, las instituciones, los conocimientos y los imaginarios que tejen los otros mundos de vida. Se trata del reconocimiento de la diferencia y la diversidad "para remover los cimientos filosóficos, culturales, políticos y sociales de esta civilización hegemónica, homogeinizante, jerárquica, despilfarradora y excluyente (Inciso 8 del Manifiesto por la Vida).

Levi-Strauss en 1955 vislumbraba el problema del devenir de la acción de los humanos hacia la entropía proponiendo que la antropología debiese en entropolo$g^{\prime} a^{2}$. Sin embargo, la acción humana global tiene sus diferencias, las mismas que aquí queremos esclarecer.
La ecología política se funda en la deconstrucción teórica en la arena política más allá de reconocer la diversidad cultural, los conocimientos tradicionales y los derechos de los pueblos indígenas, ante la potencia hegemónica y la ideología del "crecimiento económico ilimitado" del mercado como el destino de la historia humana. Se está confundiendo deliberadamente en los ámbitos políticos, económicos y en la geopolítica de la biodiversidad, el concepto de "desarrollo sustentable" con el de crecimiento sostenido, lo que prolonga e intensifica los procesos de apropiación destructiva del llamado "capital natural". "La racionalidad económica carece de flexibilidad y maleabilidad para ajustarse a las condiciones de la sustentabilidad ecológica" (Leff, 2002, p. 481).

El sello actual de la globalización es la crisis socioambiental a una escala mundial nunca antes vivida por la humanidad que se expresa día a día por el cambio climático global y sus repercusiones regionales, así como la destrucción de los tejidos sociales por migraciones masivas, desplazamientos territoriales y hacinamiento urbano. La salida técnico-económica del "capitalismo verde" no ha demostrado su eficacia para evitar el cambio climático global generado por el uso indiscriminado de la energía fósil y la devastación ambiental. "Los problemas significativos que enfrentamos, no se pueden resolver con el mismo nivel de pensamiento en que estábamos cuando los originamos" diría Albert Einstein. Están violentados los mismos pivotes de la vida, de la resiliencia social, ambiental, los múltiples ajustes dinámicos del equilibrio y los mecanismos de autorregulación. La creciente e imparable producción de entropía, a la que hoy asociamos el cambio climático y sus repercusiones regionales, es generada sobre todo por el incremento en los insumos de naturaleza, de materia y energía, que demanda "el crecimiento económico ilimitado" (Daly, 1999), el cual se disipa en el metabolismo industrial, por el uso de recursos fósiles y orgánicos de petróleo, carbón y bosques, que degrada la materia y la energía en un proceso económico globalizado y en el crecimiento continuo (Georgescu-Roegen, 1971)..

\footnotetext{
${ }^{2}$ Lévi-Strauss saw in the entropy law, an ineluctable trend in the destruction of nature and ecological decay that embraces cultural organization and the destiny of humanity, suggesting that Anthropology should turn into Enthropology (Lévi-Strauss, 1955)... "These authors are forerunners of political ecology by having pointed out the limits of a civilizatory process from which the environmental crisis emerged and the power struggles involved in the social appropriation of nature". En Leff (2012).
} 
Nos dice el Informe Stern (2007) sobre el cambio climático. "El cambio climático constituye el mayor fracaso del mercado jamás visto en el mundo, y interactúa con otras imperfecciones del mercado". En la misma tesitura pero desde el el ángulo de la economía ecológica del cambio climático véase también Martínez Alier (1998, p. 148 y sigs). La economía globalizada no es cíclica afirma Martinez Alier, se trata de la necesidad del flujo de energía y de recursos naturales constante, ya que el reciclado abarca solo $6 \%$ de toda la materia prima. La economía contemporánea es una sociedad global de riesgo analiza Beck (2006). En estas condiciones la muerte térmica del planeta sigue inexorablemente su camino. Asímismo, el mundo globalizado permeado por las lógicas del mercado, establece una relación colonial totalitaria y abismal con "otros mundos" incluyendo a la naturaleza. Así para producir energía nuclear, extraer los últimos minerales de la tierra, hidrocarburos de toda índole, desarrollar y imponer comercialmente la tecnología de organismos transgénicos para una agricultura industrializada, o construir represas de magnitudes considerables, se requiere enormes concentraciones de poder científico, económico y estatal al servicio de las empresas globalizadas. El conocimiento tecno-científico no está exento de esta versión totalitaria y excluyente de otros conocimientos, saberes y creencias. Se trata de un enfrentamiento frontal de epistemes que excluyen los saberes y conocimientos llamados tradicionales. En esta etapa de producción de conocimiento científico, los Estados apoyan cada vez menos la investigación pública, independiente a la vez que la producción de la ciencia en instituciones públicas o privadas depende crecientemente de los apoyos de las grandes empresas. Se trata de una realineación de los temas a investigar en donde hoy en día la racionalidad del poder económico de "competitividad" y "productividad" incluyendo la tecno-científica, domina ideológicamente sobre la éti- ca y una racionalidad ambiental. Los que resolvieron técnicamente la construcción de la bomba atómica no fueron los que ordenaron explotarla; tampoco los que construyendo robots para las guerras actuales y del futuro son los que mueven los botones devastadores. Lo totalitario del mercado y de la ciencia es precisamente el pensamiento abismal dual que separa a los humanos entre sí y a éstos de la naturaleza. El proceso de globalización requiere la facilitación estatal como plataforma para establecer tratados de libre comercio, aparatos jurídicos supranacionales, o la construcción de la infraestructura para transformar los nuevos territorios ocupados por los megaproyectos ${ }^{3}$, pero también de un aparato tecno-científico para una renovada forma de apropiación de la naturaleza que necesariamente deviene en un ecocidio masivo. El ecocidio no se realiza en espacios sin gente. La racionalidad económica prima sobre cualquier otra cuando se desplaza a los moradores campesinos de sus territorios, se destruye y privatiza el bien común, incluyendo la ciencia y el conocimiento tradicional histórico essubalternizado y invisibilizado. Las nuevas territorializaciones de los megaproyectos tansnacionales en América Latina involucran a las enormes concesiones mineras principalmente para la minería industrial o a cielo abierto, a la ocupación de territorios por nuevos complejos industriales, al despojo de territorios para fracturación hidráulica para extraer hidrocarburos, grandes hidroeléctricas, y el avance de desiertos verdes con organismos genéticamente modificados (GM) como la sojaGM, maíz GM, o algodónGM, plantaciones forestales en los pampas argentinas, selvas brasileñas o bolivianas,o en el cinturón maicero de Estados Unidos y India. Se trata de una renovada división del trabajo internacional territorializada en nuestros países del sur.

Para este "proyecto civilizatorio" se requiere de la violencia y que los Estados estén al servicio de las empresas, nacionales y multinacionales que dirigen los

\footnotetext{
${ }^{3}$ Es de enorme significación simbólica el hecho de que en el año 2003, la corporación Syngenta haya publicado un aviso publicitando sus servicios en los suplementos rurales de los diarios argentinos Clarín y La Nación en el cual bautizó con el nombre de "República Unida de la Soja" los territorios del Cono Sur en los que se siembra soja transgénica - (Brasil, Argentina, Uruguay, Paraguay y Bolivia). Desde el año 2012 se produjo en estos países una segunda embestida de las corporaciones del agronegocio sobre los territorios y las instituciones imponiendo nuevos transgénicos, con mayores riesgos por la aplicación de agrotóxicos y cambios en las políticas que sólo tiene precedentes en la primera imposición de los transgénicos, durante la segunda mitad de los años 90. (Vicente, 2013). Impactos socio-ambientales, evaluaciones de riesgo, participación ciudadana. Seminario Cultivo transgénicos en el Cono Sur. GRAIN y Acción por la Biodiversidad.
} 
mercados globalizados. En México, una gran parte del país está concesionada a muy pocas empresas mineras y de extracción de hidrocarburos transnacionales. En los últimos 15 años por lo menos tres millones de hectáreas en territorios indígenas han sido concesionadas a poderosas empresas mineras, así como para la extracción de hidrocarburos, las mismas que no pasaron por el mínimo protocolo de consulta indígena previa, libre y informada como lo exigen los tratados y convenios internacionales. Varias concesiones mineras abarcan el territorio completo de pueblos indígenas (Boege, 2013). Los megaproyectos en América Latina son las nuevas formas de despojo territorial masivo. Así en el nuevo proyecto de siembra de soyaGM en la península de Yucatán, México, se está fomentando el desplazamiento de campesinos mayas de sus comunidades y provocando el desmonte de miles de hectáreas de selva. Igualmente la construcción de proyectos carreteros que parten en pedazos los territorios indígenas, sin miramientos de los derechos que amparan a la población local. Hoy la mayoría de los Estados en América Latina con sus reformas estructurales, aparecen como alcahuetes de las re-territorializacion enfavor de las transnacionales en procesos literal de "desterritorialización" (Harvey, 2004) de las poblaciones originarias- indígenas, campesinas y rurales.

La disputa por las naciones fomenta tensiones socioambientales que se articulan en distintos movimientos de oposición, resistencia y la lucha de miles de pobladores, campesinos y indígenas. La "nueva ruralidad" en México está además impregnada por las luchas territoriales por el crimen organizado ligado en parte a la clase política. En estas tensiones sociales resultantes, la pregunta central sería ¿Cómo se puede construir una racionalidad cultural y ambiental (biocultural) alternativa, formada por los diferentes modos de organización simbólica y productiva, de los pueblos indígenas y de las comunidades campesinas, a la vez que estrategias alternativas de sustentabilidad? Las estrategias para una modernidad alternativa sustentable, o alternativa a la modernidad, se desarrollan desde el cosmopolitismo subalterno, que se basa en la diversidad biocultural, como bien común en espacios socioculturales y territorios ganados por distintos grupos sociales, incluyendo los pueblos indígenas.

\section{Hacia una antropología ambiental para la apropiación social del patrimonio biocultural en América Latina}

Escobar (1998, p. 296-297) nos refrenda la siguiente reflexión en su nueva compilación "Sentipensar" cuyo título rememora a otro gran pensador latinoamericano: Orlando Fals Borda, La mayoría de los conocimientos "expertos" del estado y de la academia sobre estos temas, por el contrario son anacrónicos y arcaicos y solo pueden conducir a una mayor devastación ecológica y social. Enfatiza que la historia del desarrollo puede verse desde la perspectiva de los cambios, y de las transformaciones en el régimen discursivo, y mantiene la idea de que ese discurso que detiene su mirada en nuevos actores antes no contemplados como las mujeres, el medio ambiente puede crear nuevas posibilidades de lucha y resistencia que permite adelantar perspectivas culturales alternativas. Es decir, la producción de nuevos discursos, tales como el de campesinos, feministas y ambientalistas con nuevas prácticas, no es un proceso unilateral; pues puede crear condiciones para la resistencia.

En el mismo tenor De Sousa Santos (2009) después de analizar la crisis del paradigma dominante nos anima a incursionar en nuevos procesos de producción, de valorización de los conocimientos y saberes en general:

Las epistemologías del sur son el reclamo de nuevos procesos de producción, de valorización de conocimientos científicos y no científicos y de nuevas relaciones entre diferentes tipos de conocimiento, a partir de las prácticas de las clases y grupos sociales que han sufrido, de manera sistemática,destrucción, opresión y discriminación causadas por el capitalismo, el colonialismo y todas las naturalizaciones de la desigualdad en las que se han desdoblado.

¿Qué podemos aprender de las sociedades que utilizan mínimamente la energía fósillas, cuales desde su memoria biocultural (Toledo V.M. \& N. Barrera-Bassols, 2008), desde "el kosmos, conocimiento y praxis" así como nuevas prácticas ambientales y agroecológicas construyen una ética socioambiental basada en el gobierno de los bienes comunes, en las reciprocidades entre humanos, en la economía social solidaria con la 
naturaleza y con otros objetivos o proyectos de vida fuera del consumismo globalizado?

Parafraseando a Wright Mills (2003), la segunda cuestión sería ¿necesitamos recurrir a la imaginación sociológica (en nuestro caso imaginación antropológica) para generar nuevas categorías y así aprehender las relaciones sociales en el marco de las complejidades socioambientales en nuestros países?

Cuando indagamos sobre el concepto de patrimonio biocultural, ${ }^{4}$ nos referimos al componente sustancial de las identidades de la "otredad" territorializada, sobre el campo de estudio y praxis de la relación "natura-cultural" por parte de distintos segmentos de la sociedad principalmente indígena. Este campo o tiene(n) como reflexión la caracterización de distintas ontologías según diferentes sujetos sociales. Si hemos de retomar a Descola respecto a las cuatro ontologías (Descola, 2011), existen tres que califica como premodernas y unanaturalista - la moderna: Atendiendo las premisas de la ecología política desde el sur, la modernidad tiene distintos polos ontológicos en conflicto y talvez desde la parte señalada como premoderna podamos elaborar una "modernidad alternativa" negentrópica. La visión polar tiene sus dificultades si atendemos los procesos de integración colonial, entre la cultura dominante y las subalternizadas. En efecto, existe la constante contradicción entre distintas formas de vida, de concebir la relación entre naturaleza ysociedad, de la destrucción colonial de la cultura y de la naturaleza, de procesos de hibridación cultural, de interculturalidad no crítica, de áreas porosas de intercambio o imposición cultural, de destrucción de la memoria y patrimonio biocultural, pero también resistencia, reapropiación territorial y reinvención cultural ante la crisis socioambiental global.
Referirse a los pueblos indígenas y comunidades locales o equiparables desde la polaridad arriba mencionada, es pensar sobre los otros desde nos-otros. Es interesante señalar que el español y el catalán incluyen en el nos- a los otros, no así el portugués que utiliza solo el nos como señala la filósofa Juliana Merçon ${ }^{5}$ en un conversatorio sobre interculturalidad crítica. Nos otros sería la escritura correcta para resaltar la interacción entre el nos y los otros formándose así una unidad en la diferencia. La etnografía y en general las disciplinas antropológicas que tienen el prefijo "etnos" (etnología, etnohistoria, etnoecología, etnobiología, etnobotánica, etnosicología, etnomúsicología, etcétera) tratan de expresar precisamente ese guioncito entre el nos y los otros. Pero este guioncito para el antropólogo que parte del naturalismo, es también una flecha unidireccional conflictiva, si no se aclara que la ciencia occidental construye sus epistemes de la relación naturaleza -sociedad desde el naturalismo conceptual que establece esa dualidad entre naturaleza y cultura:

\begin{abstract}
[...] que al recortar a priori ciertos campos de conocimientos y de práctica de estas sociedades (no modernas) de manera de volverlos comparables con los saberes naturalistas occidentales que tenían el valor de patrón sin preocuparse demasiado por saber si esos dominios discretos existían como tales en las categorías locales de los pueblos estudiados. (Descola, 2011).
\end{abstract}

"Muchas sociedades denominadas primitivas", escribe Descola, "nos invitan a tal superación; ellas, que jamás soñaron que las fronteras de la humanidad se detendrían en las puertas de la especie humana; ellas, que no vacilan en invitar en el concierto de su vida

\footnotetext{
${ }^{4}$ Según Alejandro Argumedo. S/F Territorios Bioculturales Indigenas: una propuesta para la protección de territorios indígenas y el Buen Vivir, Asociación ANDES, "El "Patrimonio Biocultural Indígena" se refiere a un sistema biocultural complejo, formado por partes interdependientes. El término enfoca particularmente en la relación recíproca entre los pueblos indígenas y su medio ambiente. Los componentes incluyen recursos biológicos, que van desde lo micro (genético) a lo macro (paisajes)... tradiciones y prácticas ancestrales también conocidos como “conocimientos tradicionales", incluidos los relacionados con la forma de manejar adaptativamente un ecosistema complejo y el uso sostenible de biodiversidad. Algunos componentes del PBCI, como los alimentos, agua y semillas, son colectivos porque son esenciales para los seres humanos y sus relaciones. El PBCI se refiere también a la contribución de los pueblos indígenas al mundo. También incluye las normas de comportamiento establecidas en las sociedades indígenas que son aceptadas como derechos y responsabilidades de los pueblos y tienen influencia en el manejo de los recursos naturales, también llamado "derecho consuetudinario".

${ }^{5}$ Conversatorio sobre interculturalidad, sustentabilidad y educación. Celebrado en el Instituto de Investigaciones de la Educación de la Universidad Veracruzana Intercultural el 26 de febrero de 2014.
} 
social a las más modestas plantas, a los animales más insignificantes" (Besse, 2005).

La palabra nos-otros contiene dos categorías del yo hablante: una que asocia de manera lógica o de contexto en una sola unidad, el "yo emisor" y aquellos que comigo están vinculados, cuyo nombre también hablo y me apropio de su representatividad. El nos (yo comunico) y el otros (alter) me apropio ${ }^{6}$. ¿Qué tal, si el que habla desde el nos es indígena y los otros somos los no indígenas?, $\mathrm{Y}$ es esa polaridad resistente la que debiese ser referente para construir, desde la ecología política una plataforma para la interculturalidad crítica decolonial (Walsh, 2012) para un verdadero diálogo de saberes que se establece ante un problema común. Y el que habla proviene de una reflexividad crítica desde la subalternidad. Por ello, la reapropiación biocultural como idea o concepto se refiere a la de construir imaginarios nuevos, para una modernidad alterna que incorpora las distintas visiones culturales de naturaleza.

En el caso de la relación modernidad - tradicionalidad hay reflexiones de pensadores latinoamericanos que observan el fluir entre la construcción de la cultura en América Latina y los procesos de hibridación cultural (García Canclini, 2006). En efecto, en el concepto de hibridación legitimado por la observación empírica del fenómeno se desdibuja la contradicción en las relaciones interculturales de la modernidad, colonialidad y subalternidad cultural, y deviene la desterritorialización cultural, en América Latina. Sin embrago, es sugerente la observación de Moebus (2008) respecto a las reflexiones de García Canclini:

Entrar o salir de la modernidad no presupone, de este modo, una oposición, o hasta una opción ingenua entre racionalización y tradición; centro y periferia; occidente y oriente; y, ahora, entre lo nacional y lo global, hecho apuntado con convicción por García Canclini. Por el contrario, la decisión sobre entrar o salir de la modernidad implica la adhesión o no al reconocimiento de la hibridación como base de la propia modernización latinoamericana y de la posibilidad de que la modernidad no sea un proceso lineal, sino orientado por la propia pluralidad del orden social, que gana voz solamente en un contexto de reflexividad y, como consecuencia, genera una multiplicidad de posibilidades de ser moderno.

En este tenor, observamos que los movimientos sociales indígenas, campesinos o de otras formas de comunidades locales ylos que son desplazados territorialmente, como los Sin Tierra en Brasil por ejemplo, hablan en distintos foros por sí y para sí reflexivamente sobre lo propio, territorializando bioculturalmente distintos y imaginarios con cara a lucha presente y futuro. Para este proceso de re-territorialización el bien común es todo: la tierra, el gobierno zapatista con cuotas igualitarias de género en gran rotación tanto en la política como economía, la asamblea sobre el bien común en las comunidades, el trabajo, las semillas, los bosques, el agua y el conocimiento. Los zapatistas, releen la historia de sus territorios desde su perspectiva identitaria heróica que es el sello de su movimiento, y esa relectura es la música de fondo de toda la gestión de los mismos. Se deslindan con esta relectura del mal gobierno de los "partidistas" (que "hacen política a través de los partidos"). Desde las asambleas de las comunidades y ejidos se deciden cuáles son los trabajos colectivos solidarios necesarios y cuáles pertenecen al ámbito de colectividades como el de las mujeres, cafetaleros y ganaderos. Deciden en las asambleas comunitarias cuáles son los trabajos de las familias y cómo los demás ayudan en caso que un miembro, mujer o hombre, es elegida(o) a un siguiente nivel organizativo como por ejemplo en los municipios

\footnotetext{
${ }^{6}<$ http://etimologias.dechile.net/?nosotros>. "Un yo emisor en el acto de la comunicación nunca tiene plural más que el sociativo. El nosotros indicará siempre un yo y aquellos que conmigo están vinculados por relación lógica o contexto y en cuyo nombre también hablo o me apropio de su representatividad". De la misma manera vos (vosotros puede designar en el acto de la comunicación no solo al grupo de los receptores presentes (los distintos "tú" sino también a un tú y a todos los que a él se vinculan por una relación lógica o de contexto). En su función nominativa y vocativa el romance acabó sobrecaraterizando estas formas con un otro (de alteros) de claro valor contrastivo. "alter es un pronombre, que si bien acabó despazando el alius (otro, distintos diferentes) siempre conservó el valor contrastivo. Dotado de un sufijo-alter (otro), sobre alusi (aliado), marca un elemento diferenciado necesariamente de un par asignado, unas veces al uno, otras veces "al "otro". Así se marcaba más fuertemente la distinción entre el grupo de los vinculados al yo hablante (yo y mi grupo, que son "los "unos") frente al grupo del oyente (vosotros que sois "los otros").
} 
autónomos rebeldes zapatistas. Desde el poder sobre la gestión territorial se decide la defensa de los bosques y se formulan acuerdos y reglas sobre la gestión del bien común a través de reglamentos internos. Es decir, para la gestión del patrimonio biocultural hay reglas implícitas según la ética consensuada, explicitadas y decididas colectivamente. En este sentido no cabe aquí la "tragedia de los comunes". Para fijar las reglas de acceso no se trata de una reflexión global sobre la crisis ecológica, sino de un proceso de reflexiones particulares desde una nueva ruralidad en un proceso de reapropiación biocultural. Este proceso sucede especialmente en relación con la propiedad de las semillas o cultivares. El patrimonio biocultural referente a los recursos fitogenéticos y faunísticos domesticados se construyó como bien común en un proceso histórico colectivo de intercambio libre de semillas y propágulos. Mismo que choca frontalmente por las nuevas leyes de semillas y bioseguridad, "monsanto" que tratan de controlar la propiedad intelectual a partir de los derechos de obtentor. Estas plantas de "uso común" de los indígenas y campesinos sobre todo en los centros de origen y diversificación genética, son un patrimonio invaluable para la defensa contra los intentos privatizadores de las grandes compañias semilleras transnacionales secundados por los Estados promotores de las mismas. Por ello, a la diversidad biocultural habría que agregarle el concepto de patrimonio en el sentido de "protegiendo lo nuestro". Y en ese espíritu los zapatistas se solidarizan con los pueblos indígenas que luchan por sus territorios y sus recursos naturales. <https:// redlatinasinfronteras.wordpress.com/2008/03/23/zapatismo-y-medio-ambiente/>.

No se trata de patrimonializar la diversidad biocultural para determinado proyecto turístico nacional o regional, en el afán de folclorizar el patrimonio; se trata de la reapropiación legítima del propio (valga la redundancia) en un territorio determinado como respuesta a la crisis socioambiental y civilizatoria con cara al siglo XXI. Se trata de la reflexión de lo propio en movimientos que movilizan el patrimonio biocultural como contraste frente a los pivotes que lo destruyen, mismo que se expresa como veremos más abajo en la idea de Vivir Bien.

Según la temática propuesta en este seminario habría que preguntarse ¿Quién es ese sujeto que se reapropia del patrimonio biocultural? En el libro el Patrimonio
Biocultural de los Pueblos Indígenas de México (2008), pensé desde México en los pueblos originarios y comunidades locales para la defensa de su patrimonio con un fuerte ingrediente territorial, por ejemplo mesoamericano, andino o selvático (etcétera), que son laboratorios históricos de la domesticación y diversificación de la agricultura o del manejo de la naturaleza. Obviamente, podemos ir sumando otras experiencias socioambientales como nos sugiere Escobar en la obra arriba citada. Así el Movimiento Sin Tierra, que no es indígena, no sólo intenta lograr la recuperación de miles de hectáreas de tierras ociosas de los latifundios, sino desarrollar una alternativa cultural de carácter éticosocial de los empobrecidos, que busca alternativas productivas desde la ciencia agronómica agroecológica y agroforesterestal, así como la educación hacia la tierra como un ser vivo. La agroecología y la agroforestería de los pequeños productores se basa en el uso energético solar, que se expresa en forma de biomasa, en bajos insumos exteriores, en el respeto y mejoramiento del suelo, en el rescate de las semillas y cultígenos como bien común. ¡Qué tan lejos está esta filosofía y ontología de la tierra, en relación con la de los grandes latifundios, o los páramos verdes de la producción industrial de biocombustibles, sojaGM, maíz GM, de ganado productor de gases invernadero versus las selvas y sabanas de la agricultura industrial de las grandes transnacionales!

Las estrategias agroecológicas se basan en el patrimonio biocultural colectivo escrito con minúsculas. El sujeto, o sujetos que se apropian del patrimonio biocultural en este caso son las organizaciones en movimiento, como también los pueblos indígenas en sus territorios reconocidos o no por los estados nacionales. Su definición aún en los tratados internacionales sobre derechos indígenas y campesinos (incluyendo los "Farmers Rights", FAO, 1989), se refiere por lo menos a 370 millones de unidades de producción de campesinos y indígenas (IIED, <http://biocultural.iied.org $>$ ) que en el planeta son quienes construyen una economía local, y que representan saberes plasmados en una memoria biocultural históricamente construida a través de la práctica que cincelan los paisajes con miles de cultivos y variedades de ganado, plantas medicinales, alimentos de recolección semicultivados, generando cuidando y custodiando ecosistemas, determinados recursos fitoge- 
néticos propios. La agricultura industrial acapara el 75\% de la tierra arable del planeta, el 75\% de los combustibles fósiles y agua usados en agricultura, pero solamente es fuente de alimentos del $30 \%$ de la población mundial (Grain,2014)

Es decir, al reapropiar su patrimonio biocultural hay un sujeto social que se ve en el espejo de la identidad cuestiona y se moviliza, alrededor de su memoria biocultural (Toledo y Barrera-Bassols (2008). La reapropiación del patrimonio biocultural es un proceso de afirmación y reinvención cultural ante los procesos de su destrucción colonial, despojo y la pérdida de identidad. La identidad cultural indígena no se refiere a cualquier diversidad cultural ni cualquier proceso identitario relacionado como sería por ejemplo la de una comunidad religiosa, gremial o política. La identidad indígena está principalmente ligada a territorios ancestrales y está acotada con por lo menos tres componentes generales importantes. Un primer elemento proviene de una continuidad originaria que tiene su origen desde antes de la constitución de las naciones latinoamericanas, que llamaremos matriz cultural, sostenida por los grupos domésticos familiares y artesanales que van ocupando el territorio tal como lo observamos hoy. Hoy en día solo son pocas las familias que no tengan un familiar migrante y el ser indígena migrante genera nuevos contrastes identitarios y ventualmente ligados a imaginarios territoriales pero que con el tiempo se desdibujan. Este concepto de continuidad originaria no se traduce en inmovilidad social, pero si en cierta inmanencia aun cuando sus componentes se adapten y se transformen constantemente según las nuevas situaciones externas e internas. Es precisamente la adaptabilidad cultural que permite darle continuidad a esta "matriz cultural". Sin embargo, no se trata de continuidades lineales. La anterior aseveración nos lleva a un segundo componente de la construcción de la identidad cultural indígena que se define por el contraste constante con las demás identidades, es decir, con otros pueblos indígenas, con los mestizos, con los comerciantes acaparadores, con los parientes urbanos, con los aparatos educativos, eclesiásticos o denominaciones cristianas o el propio aparato estatal y sus políticas de gobierno, en un fluir contradictorio con muchas aristas, algunas porosas culturalmente y otras no. Un tercer componente es la idea de re-territorialización reflexiva desde la diversidad biocultural, bajo nuevos y viejos principios, valores y fines.

\section{Etiología del concepto patrimonio biocultural.}

El concepto de "bio-cultura" obliga desarrollar métodos, teorías y etnografías que analicen unitariamente la relación naturaleza-sociedad, misma que ha sido separada ontológicamente de manera dual por el naturalismo de la civilización y ciencia occidental. Al contrario del naturalismo, la concepción y vivencia de naturaleza y los seres que la organizan y la habitan, están inextricablemente relacionados con los humanos, son parte de ella, además dadora de la vida, del sustento, con la cual hay que entrar en una relación de reciprocidad. Se trata de una relación entre sujetos con capacidad de agencia de las dos partes y que construyen una relación ético social que no se puede trasgredir.

Tenemos en la compilación realizada por L. Maffi (2001) que se refiere a la diversidad biocultural que vincula lengua, conocimiento (tradicional) y medio ambiente. Se trata de un primer acercamiento temático en un esfuerzo colectivo para abordar desde una nueva plataforma epistemológica, la visión de la relación naturaleza-sociedad desde la antropología y la lingüística.

Originalmente, el concepto se perfila en los campos antropológicos desde la etnolingüistica relacionada con la diversidad biológica así como por la defensa de los "conocimientos tradicionales" a nivel internacional en relación con el medio ambiente. En los distintos capítulos de la compilación citada se van construyendo los temas relevantes entre ellos como el de co-evolucióny la interdependencia de las diversidades cultural, lingüística con la biológica (Biocultural hotspots en inglés). De manera inquietante Harmon (1996) nos describe como la diversidad cultural y la diversidad de lenguas están inextricablemente ligadas a la diversidad biológica. Así 10 de 12 países megadiversos (que conforman $83 \%$ de toda la biodiversidad mundial) están en la lista de los 25 países que tienen la mayoría de lenguas endémicas. Se discute el concepto de la lengua "endémica" que codifica las prácticas, relacionada al conocimiento "tradicional" y el manejo de los ecosistemas comparándola con las 
lenguas cosmopolitas que no dependen directamente de los ecosistemas ni conviven con ellos, por lo que no codifican el entorno inmediato en su imaginario (Dasman, 1994, citado en Maffi, 2002). Es precisamente lo que V.M. Toledo propone, una disciplina científica etnoecología para describir la interacción unitaria del "kosmos" como el sistema de creencias, "corpus" el sistema de conocimientos y praxis (KCP) el conjunto de prácticas productivas (Toledo, 2002). Asimismo hay una transformación epistemológica de la etnobiología en México y en América Latina, donde los conocimientos tradicionales se dialogan sobre una plataforma de interculturalidad crítica para un diálogo de saberes horizontal y un código de ética decolonial. ${ }^{7}$

Wollock (p. 255, citado en Maffi, 2001) en su reflexión sobre el papel de las lenguas en la interpretación de la naturaleza, nos dice que hay que migrar, del análisis de la lengua como gramática (no importa cuán universal sean los patrones), hacia la lengua como guía de patrones de la acción humana. Un tema igual de inquietante es la relación entre la pérdida de las lenguas indígenas, la pérdida de la biodiversidad y el conocimiento tradicional.

La clasificación de la naturaleza por las etnociencias, ligan los conocimientos a una práctica con nomenclaturas etno-geo-fisica-biológicas simbólicas (toponimias) en una cartografía que unifica el territorio físico con el simbólico, que se refiere a las metáforas y metonimias, del simbolismo fonético, y la onomatopeya, el estudio psicofisiológico de relaciones entre percepción, imaginación, memoria, signos de acción humana incluyendo el discurso (Wollok, 1997 citado en Maffi, 2001).

Se estima que en el planeta existen actualmente más de 6.700 (seis mil y setecientas) lenguas orales (Ethnologue, 2005). En México, según el Instituto Nacional de Lenguas Indígenas (INALI, 2007) ${ }^{8}$ tenemos 11 familias lingüísticas, 68 agrupaciones lingüísticas y 364 variantes lingüísticas, que deberían denominarse lenguas cuando son ininteligibles entre ellas. Este hecho nos muestra una riqueza cultural y biológica extraordinaria que coloca a México junto con otros países latinoamericanos, como uno de los 10 países con mayor diversidad lingüística del mundo. Varias lenguas pertenecen a comunidades relativamente pequeñas, en riesgo de desaparecer. En el caso de México y Centroamérica es especialmente importante esta discusión, ya que todas las lenguas orales y sus variantes de los pueblos indígenas son "endémicas" al localizarse únicamente en determinadas regiones geográficas (salvo aquellos hablantes que la practican en los procesos de migración), y éstas representan una filosofía práctica alrededor de territorios, ecosistemas y actividades transformadoras (Boege, 1988; 2008), constructoras de identidad. Muchas son lenguas que no tienen literatura escrita que las unifiquen en entidades lingüísticas mayores, su pérdida es equiparable con las especies o ecosistemas. Esto es, el conocimiento tradicional que es de naturaleza práctica, se transmite y se forja oralmente. Si se pierde una lengua, la humanidad habrá perdido una parte del conocimiento sobre los paisajes, ecosistemas y modos de apropiación de los mismos. Junto con la lengua, la humanidad habrá perdido para siempre un cúmulo de experiencias que parten del conocimiento cultural de las relaciones humanas ligados a los saberes ambientales, de las formas de vida y las concepciones del mundo de sus hablantes. (véase también de Avila, 2008). Mühlhäulser (1996) ha elaborado la noción de "ecologías lingüísticas" que se definen como relaciones de redes que no solo se refieren al ambiente lingüístico y social, sino a los imaginarios que están profundamente relacionados con comportamientos ético-sociales con el medio ambiente. Las lenguas "endémicas" son entonces un instrumento cultural poderoso para codificar los imaginarios socioambientales, territorializados y generados en la praxis cotidiana en esta memoria biocultural.

En nivel global el 90\% de las lenguas nativas desaparecerán en los siguientes 100 años (Oviedo et al., en Maffi, 2001). Por lo tanto, es crucial entender la crisis de extinción de las especies en el siglo XXI, en relación tanto de la misma naturaleza como de la memoria

\footnotetext{
${ }^{7}<$ http://etnoecologia.uv.mx/Red_Paginaprincipal.html $>$.

${ }^{8}$ Esta clasificación de las lenguas indígenas tiene un reconocimiento oficial y éstas se encuentran referidas en el Catálogo de Lenguas Indígenas Nacionales, publicado el 14 de enero de 2008 en el Diario Oficial de la Federación (DOF 14 de enero de 2008).
} 
biocultural, con ello se sellaría la disrupción del complejo entramado de las relaciones en el medio ambiente, cultura y social . Como consecuencia de esta crisis de las adaptaciones locales a los ecosistemas, se pierden servicios ambientales, biodiversidad, agrodiversidad, paisajes, sistemas alimentarios, trabajo y economías solidarias, a favor de la producción de mercancías producidas en economías de escala, ahora en un proyecto global neoliberal. En este contexto Chapin (1992) afirma que la adaptación, resistencia y renovación frente a estas situaciones adversas por parte de las culturas locales y de los pueblos indígenas se da cuando éstas logran mantener su autonomía en la toma de decisiones, y podemos agregar retener y desarrollar el control cultural (Bonfil, 1988) en estos procesos de cambio. Es decir, las luchas por la autonomía, los acuerdos indígenas para la acción común, y el gobierno de los bienes comunes (Ostrom, 2000), el trabajo y economías solidarias y el control cultural del bien común, serían temas centrales también para la defensa y conservación de los paisajes bioculturales y funcionalidad de los ecosistemas.

Ante el grave deterioro de los ecosistemas en nivelmundial se desarrolla aquí la hipótesis que hay una relación causa efecto vinculada entre la extinción de las lenguas y de la biodiversidad con la pérdida o desplazamiento de las lenguas "endémicas" como repositorio del conocimiento tradicional o como memoria biocultural (Toledo \& Barrera-Bassols, 2008). Para Wollok (en Maffi, 2001, p. 255-256) no hay duda: cuando se extingue una lengua, desaparece la memoria, el conocimiento y la manera de conservación de la biodiversidad generada por cientos o miles de años.

De los 25 países con mayor número de lenguas indígenas, 10 son países megadiversos. Estas correlaciones se deben, entre otras, a la variedad de suelos, ecosistemas, climas, barreras geográficas y economías de subsistencia con cultivares propios adaptados y de intercambio local y regional. Si usamos las dos matrices (diversidad cultural y diversidad biológica) y la analizamos en una dinámica evolutiva a través de la domesticación de las plantas y la conformación de paisajes culturales, México y Guatemala estarían juntos en segundo lugar mundial biocultural ${ }^{9}$ a la vez uno de los centros de origen, domesticación y diversificación genética de la agrobiodiversidad (Centros de Origen Vavilov). La accidentada geografía con sus barreras serranas formidables y los ensambles ecosistémicos cambiantes (diversidad beta) es la base de agroecosistemas que se construyen en procesos de domesticación y diversificación de la agrodiversidad, de los agroecosistemas y sus recursos fitogenéticos. La sostenibilidad ambiental en la lucha de los pueblos de América Latina es central para el mantener, custodiar y desarrollar este patrimonio biocultural. El mismo estudio propone la posibilidad de que fenómenos ecológicos de pequeña escala se deban a esta correlación de la diversidad biológica-lingüística y cultural, en donde las poblaciones adaptan sus culturas a las características ambientales y transforman el ambiente a partir de sus conocimientos. Para México significa la adaptación civilizatoria colonial a la matriz mesoamericana principalmente en la cultura del maíz y viceversa. Este concepto es de suma importancia, ya que los grupos indígenas y comunidades locales en la línea del tiempo, generan paisajes en donde se interviene, se selecciona y genera una diversidad regional. Por otro lado, al crear estos agroecosistemas se desarrollan sincrónica y diacrónicamente elementos complejos de coevolución entre las especies cultivadas, insectos hospederos o simbiosis entre leguminosas, bacterias fijadoras de nitrógeno y las gramíneas como el maíz. Es decir, al usar la energía fotosintética y la diversidad biológica como aporte energético constante y tomando en cuenta los policultivos simbióticos, no se altera sustancialmente el ciclo global del carbono o del nitrógeno y son agroecosistemas que se pueden denominar sistemas negentrópicos. Por lo anterior, un componente importante del patrimonio biocultural está constituido por los agroecosistemas y sus recursos fitogenéticos y de fauna aveces endémicos, o bien por especies que forjaron al sistema alimentario mundial y que, en el caso de Mesoamérica, corresponde al $15.4 \%$ de todas las especies empleadas (Conabio, 2006). Se trata de recursos (fito) genéticos y de fauna, que siguen estando presentes en las regiones bioculturales. Las especies domesticadas o construidas culturalmente

${ }^{9}<$ http://etnoecologia.uv.mx/pdfs/Red\%20de\%20Etnoecolog\%C3\%ADa-22.pdf $>$. 
en Mesoamérica se componen de más de 200 especies y miles de variedades, algo similar al caso andino respecto a las papas y otros tubérculos.

Para darnos cuenta en nivel mundial del choque civilizatorio que implica la agricultura industrial versus la agricultura tradicional, Esquinas (2003) de la FAO nos dibuja el siguiente panorama: Menos de 120 especies de plantas cultivadas proporcionan al sistema alimentario mundial el 90 por ciento de alimentos. Sin embargo, el $70 \%$ se concentran en sólo 20 especies vegetales y cinco especies animales. Únicamente cuatro especies (maíz, papa, arroz y trigo) y tres especies (vacas, cerdos y pollos) aportan más de la mitad. Esta reducción peligrosa de especies y sus variedades se acentúa con el control de las semillas por pocas empresas transnacionales que generan variedades cada vez más especializadas sin plasticidad genética adaptativa (Fowler \& Mooney, 1990) por ejemplo al cambio climático global. Mientras que los millones de indígenas y campesinos con su patrimonio biocultural custodian el acervo de la diversidad de las especies comestibles y medicinales por ellos domesticados o usados milenariamente, los negociantes de la agricultura industrial junto con los ministerios de agricultura de los países latinoamericanos están provocando la erosión genética de las especies comestibles usadas comercialmente, reduciendo el uso masivo a pocas variedades producidas en condiciones de laboratorio o parcelas experimentales. Por la plasticidad genética y su siembra en múltiples ecosistemas la diversidad de las semillas nativas tienen un potencial importante para resistir el cambio climático. El maíz en México se cultiva por ejemplo desde los 0 metros de altitud, hasta los 3000 sobre el nivel del mar y en un régimen de lluvia entre los $200 \mathrm{~mm}$ hasta los $4500 \mathrm{~mm}$. Ningún laboratorio o empresa transnacional podría repetir esta proeza biocultural de los pueblos indígenas y campesinos. Por eso, la biopiratería para las empresas es tan importante.

Desde la Ecología Política, es imprescindible basar los desarrollos de una modernidad alternativa en bienes comunes colectivos como son el acervo fitogenético y conocimientos tradicionales que plasmamos en el concepto de patrimonio biocultural como bien común. Es V.M. Toledo et al. (2002) sugieren que México y Centro América conforman una de las regiones bioculturales más ricas del mundo en bioculturalidad. Una flora de enorme riqueza se sobrepone a más de 300 pueblos indígenas si los hemos de clasificar por sus idiomas. Para ello nos propone sobreponer las áreas de mayor diversidad biológica con los territorios indígenas. Con esta metodología y afinando los sistemas de información geográfica se le agregó (Boege, 2008) el concepto de Centros de Origen, domesticación y diversificación genética (constante) de Vavilov, lo que dio más conceptos y datos de esta enorme riqueza biocultural (Toledo et al., 2013). Es decir, el asombro sobre esa riqueza biocultural negada por los Estados aun los que se dicen pluriculturales, así como por la cultura sociedad y economía dominante, me motivó la introducir el concepto de patrimonio biocultural en nuestras discusiones (Boege, 2008). Esto es, se trató de posicionar y dar visibilidad a los pueblos indígenas y comunidades equiparables, en su legado desarrollado históricamente en sus territorios. La intención de incorporar el concepto de patrimonio al de la diversidad biocultural con escritura minúscula fue para incitar el reconocimiento de lo propio, como legado colectivo que da identidad en el presente, y una plataforma para el proyecto de colonial futuro. Asimismo, se trató de hacer visible un proceso civilizatorio negado (Bonfil, 1987) por la sociedad dominante. Esto es, en México los recursos fitogenéticos domesticados y semidomesticados, sus agroecosistemas están ligados a la "milpa", un policultivo cuyos elementos centrales son el maíz, calabaza, frijol, y un gran número de plantas semicultivadas o toleradas asociadas. La gestión de la milpa en los ecosistemas naturales conforma paisajes culturales construidos en un ir y venir de flujos génicos entre las plantas domesticadas y sus pares silvestres. Pero también la milpa es un laboratorio de la diversificación genética cuando se dispersa como método agronómico en todo el continente americano, incluso antes de la conquista española. Se crean así nuevos centros de origen secundarios que generan nuevas razas y variedades de maíz por ejemplo. La milpa es emblemática puesto que ha alimentado a millones de personas y puede considerarse que "haciendo milpa" es una metáfora de las estrategias de la diversidad. Otro gran ejemplo son los cultivadores andinos de papa en sus agroecosistemas complejos. Así por ejemplo, la defensa biocultural de la papa en Cusco, Perú por cuatro comunidades quechuas en los "parques bioculturales de la papa", manejando alrededor de 1500 
variedades de papas, varias resistentes a enfermedades, a la sequía o a las heladas. La conciencia de su riqueza por parte de los indígenas de estas comunidades andinas, motivó la exigencia de repatriación de los cultígenos colectados por instituciones internacionales y nacionales.

Cuando me propuse integrar la categoría de patrimonio a la diversidad biocultural (Boege, 2008), pensé en algo parecido a lo que el International Institute of Environment and Development (IIED por sus siglas) entiende como "biocultural heritage"10 que se puede traducir como legado biocultural, aunque Argumedo (s.f.) prefiere traducirlo como patrimonio biocultural.

El IIED tiene cuatro bloques de pensamiento práctico para acercarse al patrimonio biocultural: 1) La formulación teórica, que desde un inicio contiene las tesis que pone de manifiesto la riqueza, defensa local y regional del patrimonio biocultural. 2) Desarrollo de instrumentos colectivos para el diálogo de saberes bajo un objetivo común entre grupo facilitador y los y las conocedores locales. El objetivo común es el diseño de la investigación, instrumentación y reapropiación de los recursos fitogenéticos y desarrollar tecnologías sustentables propias para diseñar una línea de vida que fortalece las economías locales y regionales de manera endógena. 3) Los desarrollos en base al patrimonio biocultural han de ser blindados jurídicamente de tal manera que se garantice la repartición equitativa de beneficios. Esto significa que cualquier institución o investigador (a) que desea estudiar el patrimonio biocultural tiene que responder a códigos de ética y construcción de un protocolo consensuado con asambleas comunitarias, que necesariamente conlleven la reflexión grupal sobre la importancia de lo propio, y el manejo y destino de los resultados. 4)A partir de la implementación práctica de la investigación con investigadores comunitarios (nombrados en asambleas o por grupos focales del proyecto; tendrán que ser definidos en igualdad de circunstancias de investigación los términos de investigación comunitaria, con el objetivo de obtener el inventario biocultural bajo lineamientos previamente acordados. 5) El último principio es impulsar protocolos bioculturales comunitarios de defensa y custodia comunitaria de sus recursos fitogenéticos, de sus conocimientos tradicionales y los términos de custodio como comunidades de conservación y desarrollo comunitario in situ así como su enriquecimiento. 6) El custodio, enriquecimiento e investigación comunitaria del germoplasma (vegetal y faunístico utilizados) así como desarrollo de los agroecosistemas con sistemas agroecológicos genera estrategias de soberanía alimentaria en base a la alimentación culturalmente construida. Se trata de una estrategia de desarrollo endógeno basado en la tradición, renovación creativa en base a las diversidades. Además se desarrollan metodologías para la protección de derechos consuetudinarios comunitarios y conocimientos tradicionales así como de todo el patrimonio biocultural, $(<\mathrm{http}$ :/pubs. iied.org/pdfs/14591IIED.pdf?>). Así el IIED se refiere al concepto de patrimonio biocultural como una herramienta que décuenta de una relación compleja e interdependiente entre pueblos indígenas y la naturaleza.

En resumen, el patrimonio biocultural se refiere también a los recursos biológicos o fitogenéticos silvestres, semidomesticados y domesticados, que van desde la variabilidad genética (genes), hasta los sistemas de uso incluyendo los agrícolas, paisajes a distintas escalas, forjados según las prácticas y conocimientos indígenas tradicionales. El patrimonio biocultural se refiere también a los imaginarios socio ambientales que construyen éticas locales de aproximación e integración unitaria a la naturaleza, cosmovisión que con frecuencia se puede vincular a los mitos de origen y reelaboraciones constantes en esa tensión de colonialidad y resistencia.

\footnotetext{
${ }^{10}$ Biocultural Heritage $(\mathrm{BCH})$ refers to the knowledge and practices of indigenous people and their biological resources, from the genetic varieties of crops they develop, to the landscapes they create. As indigenous peoples have adapted to harsh climates over many generations, this heritage is important for food security in the face of climate change. Biocultural heritage is held collectively, sustains local economies and is transmitted from one generation to the next. It includes thousands of traditional crop and livestock varieties, medicinal plants, wild foods and wild crop relatives. These precious resources have been conserved, domesticated and improved by communities over generations - and sometimes millennia. We all rely on biocultural heritage for food and health security, particularly in the face of climate change risk and uncertainty. For some 370 million indigenous people who depend directly on natural resources and are vulnerable to climate change, this heritage is vital for survival. It is also closely linked to their cultural identity and religious beliefs. $<$ http://biocultural.iied.org $>$.
} 
La humanidad depende de la diversidad para su sistema alimentario. Con el concepto de patrimonio biocultural no se trata de "patrimonializar" desde el exterior un legado biocultural para ser enajenado por terceros; se trata de un bien común no privatizable como herramienta de defensa de las diversidades culturales y biológicas. Tampoco se trata de hacer museos bioculturales regionales. Se trata de un proceso de re-conocer por parte de la población local y regional el valor de su custodio histórico y que puede desencadenar procesos de una modernidad alternativa, creativa y auto-reflexiva con un fuerte ingrediente de colonial. Las varias experiencias de fortalecimiento del patrimonio biocultural vía la construcción de proyectos regional es autonómicos y endógenos a diferentes escalas, nos indica, que se trata de procesos de empoderamiento y contra conducción por parte de colectivos que resisten o resignifican las políticas públicas, económicas, educativas sociales y culturales coloniales y destructivas que impone el mercado y el estado. Es decir, las acciones violentas actuales de los Estados latinoamericanos que en nombre del interés público preferente cede a compañías estatales y/o transnacionales territorios indígenas y campesinos completos, genera múltiples formas de resistencia ante situaciones particulares, lo que desencadena la movilización socioambiental en donde el componente biocultural es clave.

\section{El patrimonio biocultural, regiones, territorios y tierras}

El concepto de patrimonio biocultural no sólo nace en el ámbito académico sino de la preocupación expresada en el año 2005 en las Naciones Unidas por grupos indígenas ${ }^{11}$ y comunidades locales - respecto al fenómeno creciente la biopiratería y la consecuente falta de respeto a los derechos biológicos colectivos y los conocimientos tradicionales, ${ }^{12}$ asociados. El concepto de conocimientos tradicionales ligados a la biodiversidad y su uso ha sido posicionado en el derecho internacional en el artículo $8 \mathrm{j}^{13}$ del Convenio de Biodiversidad y en las sucesivas Conferencias de Partes (COPS) en donde se incluye también la agrobiodiversidad. En la era de la información, la biopiratería, bioprospección y el tema "de quién son los recursos fitogenéticos" requieren de una respuesta nacional e internacional. La apropiación de recursos biológicos colectivos por parte de terceros y el compartir equitativamente beneficios de su explotación resulta irreal por las diferencias ontológicas entre uno y otro grupo social. En este tenor de no respeto al patrimonio biocultural en México organizaciones indígenas, la Unión de Científicos Comprometidos con la Sociedad y el Centro Mexicano de Derecho Ambiental, interpusieron una queja a la Comisión Interamericana

\footnotetext{
${ }^{11}$ Quinta sesión del Foro Permanente sobre la Cuestiones Indígenas FPCI-UN de las Naciones Unidas relacionadas con la protección, preservación y promoción del conocimiento tradicional se explora el concepto "patrimonio biocultural colectivo" (Swiderska \& Argumedo, 2006).

${ }^{12}$ Los saberes y conocimientos tradicionales son un recurso no solamente para las comunidades locales, sino para toda la humanidad, en cuanto permiten preservar la diversidad cultural. Según la "Declaración de la UNESCO sobre protección y promoción de las expresiones culturales" del 2005, la diversidad cultural es patrimonio humano y debe ser reconocida y promovida a beneficio de las actuales y futuras generaciones; la diversidad cultural es necesaria para la supervivencia de la humanidad así como la biodiversidad es necesaria para la supervivencia de la naturaleza. Todas las formas de conocimiento son recursos extremamente importantes para enfrentar desafíos globales tan difíciles como, por ejemplo, el cambio climático. El conocimiento tradicional se refiere al conocimiento, las innovaciones y las practicas de las comunidades indígenas y locales de todo el mundo. Concebido a partir de la experiencia adquirida a través de los siglos, y adaptado a la cultura y al entorno locales, el conocimiento tradicional se transmite por vía oral, de generación en generación. Tiende a ser de propiedad colectiva y adquiere la forma de historias, canciones, folklore, refranes, valores culturales, rituales, leyes comunitarias, idioma local y prácticas agrícolas, incluso la evolución de especies vegetales y razas animales. El conocimiento tradicional básicamente es de naturaleza práctica, en especial en los campos de la agricultura, pesca, salud, horticultura y silvicultura.

${ }^{13}$ Artículo 8(j) del CDB. "Con arreglo a su legislación nacional, respetará, preservará y mantendrá los conocimientos, las innovaciones y las prácticas de las comunidades indígenas y locales que entrañen estilos tradicionales de vida pertinentes para la conservación y la utilización sostenible de la diversidad biológica y promoverá su aplicación más amplia, con la aprobación y la participación de quienes posean esos conocimientos, innovaciones y prácticas, y fomentará que los beneficios derivados de la utilización de esos conocimientos, innovaciones y prácticas se compartan equitativamente;La parte subrayada ha sido una de las preocupaciones en las discusiones del Protocolo de Nagoya que más abajo discutiremos.
} 
de Derechos Humanos expresada en un informe que se refiere a la "Destrucción del patrimonio biocultural de México por mega proyectos y ausencia de legislación y política pública culturalmente adecuada para los pueblos indígenas y comunidades equiparables". ${ }^{14}$

Respecto a las regiones bioculturales G. Giménez (1996) nos dice que la región no debe considerarse como un dato a priori sino una construcción fundado con diversos criterios entre otros los histórico culturales con ciertos sistemas cuyas partes actúan en mayor medida entre sí en relación con sistemas externos. En el caso de las regiones bioculturales esbozadas en el libro el Patrimonio Biocultural de los Pueblos Indígenas en México (Boege, 2008) sus componentes pueden contener uno o varios territorios con alta densidad de población indígena, y se refieren como centros de origen y producción biocultural en donde se sobreponen la diversidad biológica, los ecosistemas que devienen en paisajes culturales gestionados, la diversidad cultural que se expresa en múltiples idiomas, los recursos fitogenéticos construídos en un proceso de constante selección y diversificación, así como sistemas simbólicos que unifican el cosmos, conocimiento y práxis.

Los territorios indígenas reconocidos por artículo segundo de la Constitución mexicana por ejemplo, tienen su sustento en la libre determinación y las autonomías de los pueblos indígenas o comunidades equiparables en el marco de la Constitución. Estas simples definiciones de derechos indígenas debiesen ser el marco para decidir las formas de internas y organización social, económica, política y cultural, pero también consideradas las políticas públicas pluriculturales. Sin embargo, para la implementación práctica de auto determinación, autonomías, desarrollo, el legislador le quitó los "dientes" que estuvieron presentes en los Acuerdos de San Andrés entre el EZLN y el gobierno, y así el Estado otra vez puede reforzar en la Constitución su tutelaje del sobre los pueblos indígenas al definirlos como sujetos de interés públicos y no sujetos de derecho público.

Las disputas por los territorios indígenas y campesinos en todos los ámbitos bioculturales incluyendo los físicos no han cesado en toda América Latina. Los mega proyectos y el reconocimiento constitucional delos territorios indígenas como la totalidad de su hábitat (formula del Convenio 169 OIT), se han convertido en un tema central de disputas en el derecho nacional e internacional. En México el legislador no se imaginaba que con la firma de tratados internacionales y la jurisprudencia nacional y internacional sobre derechos humanos, podría relacionar los derechos indígenas con un bloque de constitucionalidad de derechos humanos consignados en el artículo primero de la constitución mexicana. Los territorios están siendo disputados una vez más por mega proyectos, mineros, hidroeléctricos, de hidrocarburos, de la agricultura comercial en su fase transgénica, por la privatización de las semillas, el agua, construcción de carreteras así como los recursos biológicos colectivos y las nuevas ocupaciones territoriales del crimen organizado.

Asimismo, en sus territorios los indígenas están construyendo sistemas de producción sustentables de nuevo tipo como son los del café, pimienta y miel orgánica, procesos agroecológicos para incorporarlos a mercados justos y con sellos verdes y provenientes de pequeñas producciones campesino indígenas o bien policías comunitarias en múltiples comunidades y municipios. Igualmente, el manejo forestal comunitario. Entonces, en la gestión territorial indígena a distintas escalas fluyen los paisajes bioculturales en los cuales los recursos fitogenéticos indígenas tienen gran importancia aun que muchas veces no son visibilizados en las luchas.

En el Artículo 13 y siguientes del Convenio 169 de la OIT, se determina que la utilización del término "tierras" en los artículos 15 y 16 deberá incluir el concepto de territorios, lo que cubre la totalidad del hábitat. El territorio de los pueblos indígenas de conformidad con los artículos 13 del Convenio debe tratarse entonces como territorio ancestral aún si han sido despojados en distintos momentos de su historia, inclusive la reciente. Tal vez, lo más desarrollado está en la construcción de la autonomía zapatista más no es una experiencia exclusiva. En este tenor múltiples

\footnotetext{
${ }^{14}<\mathrm{http}$ //www.cemda.org.mx/informe-sobre-la-destruccion-del-patrimonio-biocultural-de-mexico-por-megaproyectos-y-ausencia-de-legislacion-y-politica-publica-culturalmente-adecuada-para-los-pueblos-indigenas-y/>.
} 
organizaciones campesinas e indígenas, locales, regionales y a nivel nacional en diversos países de América Latina luchan regionalmente por la defensa la autonomía y autodeterminación indígenas, por la defensa de los territorios o la recuperación de las tierras usurpadas, esto es, la defensa de los bienes comunes. Se trata del control (bio)cultural de los recursos y la generación de nuevas organizaciones campesinas e indígenas. La reapropiación biocultural implica igual la relectura de la historia, cultura y tradiciones en las situaciones actuales en movimiento y emergencia.

\section{El Patrimonio biocultural y el buen vivir}

Desde la diversidad surge un concepto filosófico no académico, sorprendente, inesperado e inquietante que le da contenido a los movimientos socioambientales en América Latina una proyección filosófica radical. El buen vivirle da la espalda a las expectativas del "desarrollo" y crecimiento que se genera en la globalización. Es una crítica al desarrollo contemporáneo, al crecimiento económico ilimitado, a su racionalidad, al consumismo y a la idea de progreso y a la crisis ambiental, social y cultural.

No quisiera discutir aquí la génesis y aplicación de las distintas acepciones del buen vivir. El tema tiene una etiología indígena pero no es exclusiva. Se ancla en dos preceptos centrales: uno en resolver la dicotomía naturaleza sociedad en un plano que la naturaleza y humano son una unidad y que la primera tiene capacidad de agencia y debe considerarse como sujeto del cual el humano es parte y se ejerce la reciprocidad simbólica que le da un fuerte contenido ético: el otro es que se trata de un proyecto que la da la espalda a la idea de desarrollo occidental para construir una modernidad alternativa sobre la base de valores socioambientales sustentables.

Una ontología si bien no es una predeterminación, se construye a partir de las prácticas e interacciones tanto con los humanos como con nuestro entorno no-humano. Bajo éstas se generan historias, prácticas, mitos y creencias, que pueden ser entendidos como "relatos" que hacen asibles nuestras experiencias y acciones (Gudyñas, 2011).
Este autor nos propone tres planos para abordar el concepto del buen vivir:

1) El plano de las ideas: Crítica al desarrollo contemporáneo, su racionalidad, sus aspectos económicos y el mercado, su obsesión con el consumo o el mito del progreso continuado, sus implicaciones coloniales, y el bienvivir es una vía para superar esas limitaciones. También alcanza cuestiones esenciales como entendernos a nosotros mismos como personas;

2) de los discursos y legitimaciones de esas ideas. No celebra el crecimiento económico o el consumo material como indicadores de bienestar, ni alaba la obsesión don la rentabilidad o el consumo. Su apelación a la calidad de vida discurren por otros caminos, y además incluyen tanto a las personas como a la Naturaleza. Se abren las puertas a otras formas de hablar, escribir o pensar nuestro mundo;

3) y de las acciones concretas como proyectos políticos de cambio, planes gubernamentales marcos normativos, alternativas al desarrollo convencional. Y aquí está la diferencia de no repetir posturas convencionales que se critican y además sean viables.

La vinculación con el patrimonio biocultural con el buen vivir tanto en Bolivia como en Perú se convierte en un componente filosófico importante. Se trata del cuestionamiento de la sociedad dominante, mismo que los zapatistas formularon desde su levantamiento en Chiapas. Las mismas tesis se desarrollan por la ecología política: no hay salida dentro de la globalización a la crisis socioambiental, por ello, hay que buscar respuestas desde la diversidad biocultural.

El Programa Nacional Biocultural boliviano establece como objetivo el vivir bien en base al reconocimiento de los territorios de los pueblos indígenas, sus conocimientos ancestrales replanteados para la modernidad alternativa, la conservación de la biodiversidad y agrodiversidad y el desarrollo endógeno. Se plantean entonces el Vivir bien como alternativa al proceso destructivo del extractivismo global. Se trata del respeto de la diversidad incluyendo a la madre tierra. Se trata de un marco para generar espacios de gobernabilidad desde los 
derechos colectivos: economía solidaria, recuperación de saberes ancestrales y revolución ética, equidad de género, economías regionales endógenas, seguridad y soberanía alimentaria. En este proyecto es superada la visión abismal de la sociedad con la naturaleza. Aquí es importante el rompimiento con la visión monosémica que hace el zapatismo cuando se plantea un mundo donde caben otros mundos. Es decir, los zapatistas tratan de ejercer la autonomía territorial con gobiernos autónomos, basados en la gestión de los bienes comunes donde se discuten los términos de libertad, equidad de género, soberanía alimentaria y la construcción de valores éticos de convivencia. Este hecho político y el renovado control cultural sobre su territorio moviliza y reinventa el patrimonio biocultural versus la desterritorialización fomentada por los megaproyectos.

Se trata también de re-conocer que tienen un territorio común y reinventar los bienes comunes. Se formulan nuevas ideas para lograr la resiliencia ambiental y cultural con componentes y principios indígenas o principios éticos de grupos subalternizados. Se construye así un nuevo imaginario ambiental cultural y social, que se recrea sobre la base de las asambleas comunitarias, los acuerdos comunitarios para la gestión del territorio forestal y agua, enfoques agroecológicos y agroforestales.
Este enfoque no solo se refiere a regiones indígenas determinadas. Es un ejercicio que se puede aplicar desde control cultural por parte de los movimientos socioambientales como serían los Sin Tierra en Brasil. El buen vivir pone énfasis en la calidad de vida pero no se reduce al consumo o la propiedad. Gudyñas advierte sin embargo, que si bien se parte de la filosofía indígena de la vida es importante promover el debate en otras circunstancias y con otros actores. Aclara asimismo, que no existe un buen vivir indígena en sí. Se construyen una y otra vez desde la diversidad. El lekil kuxlejal tseltal y tsotsil reapropiado por las autonomías zapatistas es una ontología que se construye a partir de las prácticas e interacciones tanto con los humanos como con nuestro entorno no-humano. Bajo estas expresiones se generan historias, prácticas, mitos y creencias, que pueden ser entendidos como "relatos" que hacen asibles nuestras experiencias y acciones. Las ontologías, concluye Blaser, pueden ser entendidas como los determinantes de las representaciones totales, discursivas o no, de nuestros mundos. Igualmente el yeknimilis (andar bien) nahuat o existencia buena en la Sierra Norte de Puebla, México, puede relacionarse a la satisfacción de las necesidades bioculturales sobre la base de una relación recíproca entre los humanos y las naturalezas territorializadas.

\section{Referencias}

Argumedo, A. Territorios Bioculturales Indigenas: una propuesta para la protección de territorios indigenas y el Buen Vivir. S/F. Asociación ANDES. < http://www.internationalfunders.org/documents/TerritoriosBioculturalesIndigenas.pdf $>$.

Ávila de, A. La diversidad lingüística y el conocimiento etnobiológico. In: CONABIO. Capital natural de México, v. I, Conocimiento actual de la biodiversidad. México: Comisión Nacional para el Conocimiento y Uso de la Biodiversidad, 2008.

Ávila, A.; Pohlenz, J. J. Interculturalidad crítica y buen vivir desde la perspectiva latinoamericana. En: Ávila, A; Vázquez, D. (Coords.). Patrimonio biocultural, saberes y derechos de los pueblos originarios. Colección Universitaria Intercultural. Universidad Intercultural de Chiapas, CLACSO, PROMEP, INALI, 2012.
Beck, U. La sociedad del riesgo: hacia una nueva modernidad. Barcelona: Paidós, 2006.

Besse, J. M. Naturaleza y Cultura. Hypergeo, 2005. Disponible en: <http://www.hypergeo.eu/spip.php?article280>.

Boege, E. El patrimonio biocultural de los pueblos indígenas de México. Hacia la conservación in situ de la biodiversidad y agrodiversidad en los territorios indígenas. INAH, CDI, SEMARNAT, 2010. (reimpresión).

Boege E. Minería: el despojo de los indígenas de sus territorios en el siglo XXI. In: La Jornada del Campo 15 de Junio 2013. México, 2013.

Bonfil, G. México Profundo. Una civilización negada. SEP, CIESAS, 1987. 
Bonfil, G. Teoría del control cultural en los procesos étnicos”. Anuario Antropológico, Brasília: Editora Universidade de Brasília/Tempo Brasileiro, 86, 13-53, 1988.

Chapin, M. The Coexistence of Indigenous People and Environment in Central America. Research and Exploration, 8(1), 1992.

Centro Mexicano de Derecho Ambiental. Informe sobre la "Destrucción del patrimonio biocultural de México por megaproyectos y ausencia de legislación y política pública culturalmente adecuada para los pueblos indigenas y comunidades equiparables". 2014. Disponible en: <http://www. cemda.org.mx/informe-sobre-la-destruccion-del-patrimonio-biocultural-de-mexico-por-megaproyectos-y-ausencia-de-legislacion-y-politica-publica-culturalmente-adecuada-para-los-pueblos-indigenas-y/>.

Daly, H. Economía Ecológica: ¿Crecimiento Económico Ilimitado? ¡No Gracias! Disponible en: <http://www.gabitos. com/ECOVISION/template.php?nm=1254958314>. Consultado en: 2015.

Dasman, R. Wildlife Biology. Nueva York: Willey, 1964.

Fals Borda, O. Una sociología sentipensante para América Latina. V.M. Moncayo (Comp.). Siglo del Hombre Editores y CLACSO, 2009.

De Souza Santos B. Una epistemología del sur: la reinvención del conocimiento y la emancipación social. CLACSO, 2009.

Delgado; F.; Rist, S.; Escobar, C. Desarrollo endógeno sustentable como interfaz para implementar el Vivir Bien en la gestión pública boliviana. La Paz: AGRUCO, 2010.

Descola, P. Más allá de la naturaleza y cultura. En: Montenegro L. (Ed.). Cultura y Naturaleza. Aproximaciones a propósito del bicentenario de la Independencia de Colombia. Jardín Botánico de Bogotá. José Celestino Mutis, Acaldía Mayor de Bogotá, 2011.

Escobar, A. Sentipensar con la tierra. Nuevas lecturas sobre desarrollo, territoiro y diferencia. Ed. Unaula, 2014.

Esquinas, J. Una contribución importante para la construcción de un planeta sostenible y in hambre. 2003. Disponible en: $<w w w . f a o . o g / t c / t c / t c a / e s p / r e f i t o \_r s o s / t e n i b l e s . a s p \#$ nota1\#>. Ethnologue 2005.

Fowler, C.; CONABIO. Capital natural y bienestar social. México: Comisión Nacional para el Conocimiento y Uso de la Biodiversidad de México, 2006.

Fowler C.; Mooney, P. Shattering Food, Politics and the Loss of Genetic Diversity. Tucson: The University of Arizona Press, 1990.
Georgescu-Roegen, N. The Entropy Law and the Economic Process. New York: Universe Books, 1999.

Giménez, G. Territorio y cultura. Revista Sobre las Culturas Contemporáneas, México: Colima, 1996.

GRAIN. Hambrientos de tierra. Los pueblos indígenas y campesino alimentan al mundo con menos de un cuarto de la tierra agrícola mundial. Biodiversidad, 82/2014, 4, 2014.

Gudynas, E. Buen vivir: germinando alternativas al desarrollo. Agencia Latinoamericana de Información- ALAI 462, 2011.

Harvey D. El "nuevo" imperialismo: acumulación por desposesión. Buenos Aires: CLACSO, 2005. <http://etnoecologia. uv.mx/pdfs/Red\%20de\%20Etnoecolog\%C3\%ADa-22.pdf $>$.

IIED - International Institute for Environment and Development. Disponible en: <http://pubs.iied.org/pdfs/14591IIED. pdf?;>.

Informe Stern. La Economía del Cambio Climático. 2007. Disponible en: <http://www.ambientum.com/documentos/ general/resumeninformestern.pdf $>$.

Instituto Nacional de Lenguas Indígenas. Catálogo de las Lenguas Indigenas Nacionales: Variantes Lingüísticas de México con sus autodenominaciones y referencias geoestadísticas. 2008. Disponible en: <http://www.inali.gob.mx/pdf/CLIN completo.pdf>.

Leff, E. Political Ecology: A Latin American Perspective. In: UNESCO_EOLLS Joint Committee (Eds.). Encyclopedia of Life Support System (EOLLSS), Enciyclopedia of social Sciences and Humanities - Cultures, Civilizations and Human Society. Oxford UK: UNESCO EOLSS Publisher, 2012.

Leff, E. La apuesta por la vida. Imaginación sociológica e imaginarios sociales en los territorios ambientales del sur. México: Siglo XXI Eds., 2014.

Maffi, L. (Ed.). On Biocultural Diversity Linking Lenguage, Knowledge, and the Environment. Washington / London: Smithsonian Institution Press, 2001.

Manifiesto por la Vida: Por una ética para la sustentabilidad. Este manifiesto fue elaborado por intelectuales de América Latina en el Simposio sobre Ética y Desarrollo Sustentable celebrado en Bogotá, Colombia en mayo del 2002. Disponible en: <http://www.scielo.br/pdf/asoc/n10/16893.pdf $>$.

Martínez Alier, J. Curso de Economía Ecológica. Serie Textos Básicos para la Formación Ambiental 1. Programa de las Naciones Unidas para el Medio Ambiente. Oficina Regional para América Latina y el Caribe, 1998. 
Mills, W. La Imaginación sociológica. México: Fondo de Cultura Económica, 2003.

Moebus, A. Hibridismo cultural: ¿clave analítica para la comprensión de la modernización latinoamericana? La perspectiva de Néstor García Canclini. Sociológica, 23(67), 33-49, 2008.

Mühlhäusler, P. Linguistic Ecology: Language Change and Linguistic imperialism in Pacific Regions. Londres y Nueva York: Routledge, 1996.

Ostrom, E. El gobierno de los bienes comunes. La evolución de las instituciones de acción colectiva. México (UNAM/ CRIM), FCE, 2000.

Parque de la papa. Disponible en: <http://biocultural.iied.org/ film-documents-visit-guardians-diversity-potato-park $>$.

Swiderska, K.; Argumedo, A. Hacia un enfoque holístico para la protección del conocimiento indígena: Las actividades de las Naciones Unidas. Patrimonio Bio-cultural Colectivo y el Foro Permanente sobre Cuestiones Indigenas de las Naciones Unidas, 15 de mayo 2006. IIED, ANDES (Perú) y Call of the Earth, 2006.

Toledo, V. M. Ethnoecology: a conceptual framework for the study of indigenous knowledge of nature. In: Stepp, J.R.;
Wybdgan, F. S.; Zager, R. K. (Eds.) Ethnobiology and Biocultural Diversity, Georgia: International Society of Ethnobiology, 511-522, 2002.

Toledo, V. M.; Barrera-Bassols, N. La memoria Biocultural. La importancia de las sabidurías tradicionales. Junta de Andalucia: Icaria Editorial, 2008. (Perspectivas Agroecológicas).

Toledo V. M.; Alarcón-Chaires, P.; Moguel, P.; Olivo, M.; Cabrera, A.; Leyequien, E.; Rodríguez-Aldabe, A. Atlas Etnoecológico de México y Centro América. Etnoecológica, 6(8), 7-41, 2002. Disponible en: <www.etnoecologica.org.mx>.

Toledo, V. M.; Boege, E.; Barrera-Bassols, N. The biocultural heritage of Mexico: an overview. Langscape, 6, 6-10, 2010.

Vicente, A. C. Impactos socio-ambientales, evaluaciones de riesgo, participación ciudadana. Seminario Cultivo transgénicos en el Cono Sur, 2013.

Walsh, C. Interculturalidad crítica y (de) colonialidad. Ensayos desde Abya Yala. Ediciones CIDECI, Unitierra Chiapas Junetik Conatus, 2012.

Wollock, J. Linguistic Diversity and Biodiversity. Some implications for the Language Sciences. En: Maffi, L. (Ed.). On Biocultural Diversity. Linking Language, Knowledge and the Environment. Washington: Smithsonian Institution Press, 2001. 